ISSN 0103-9954

\title{
AVALIAÇÃO DA SEGURANÇA NO TRABALHO DE OPERADORES DE MOTOSSERRA NO CORTE DE EUCALIPTO EM REGIÃO MONTANHOSA
}

\section{SAFETY EVALUATION OF CHAINSAW OPERATION IN CLEAR-CUTTING OF Eucalyptus IN MOUNTAIN REGION}

\author{
Cleverson de Mello Sant'Anna ${ }^{1} \quad$ Jorge Roberto Malinovski $^{2}$
}

\begin{abstract}
RESUMO
Este trabalho teve como objetivo geral proceder a avaliação da segurança no trabalho de operadores de motosserra no corte de eucalipto em áreas montanhosas. A coleta de dados foi efetuada em uma empresa florestal na região do Vale do Rio Doce, em Minas Gerais, nos Municípios de Marliéria e Córrego Novo, no período de outubro de 1995 a fevereiro de 1996. A área estudada está inserida na região bioclimática número 5 do Estado de Minas Gerais cujo clima é classificado como subtropical úmido-subúmido, com temperatura média anual variando de 20 a $23{ }^{\circ} \mathrm{C}$, precipitação média anual variando de 1.100 a $1.400 \mathrm{~mm}$ e altitude de 200 a $900 \mathrm{~m}$, em relevo que varia de suave ondulado a montanhoso. Foram estudados os aspectos de segurança no trabalho e acidentes de uma amostra de 29 operadores de motosserra, ou seja, 45,13\% do total de operadores de motosserra da Empresa, que atuam em regiões de relevo montanhoso. A produtividade individual variou de 7,98 a 13,08 $\mathrm{m}^{3} /$ dia. A derrubada foi atividade na qual ocorreu o maior número de acidentes entre os operadores de motosserra. As partes do corpo mais atingidas foram os membros inferiores (pernas e pés) com 37,4\% das ocorrências. A falta de atenção por parte do operador foi apontada como a principal causa de acidentes no corte florestal, por 35,0\% dos operadores de motosserra. As causas humanas, somadas, representaram a opinião de $72,5 \%$ dos operadores de motosserra.
\end{abstract}

Palavras-chave: Segurança no trabalho, ergonomia, motosserra.

\begin{abstract}
The main objective of this study was the analysis of anthropometric factors of chainsaw operators in clear-cutting of Eucalyptus plantations, in mountain areas, with the purpose to understand the relationship between the somatotype and the productivity variation. The short-wood cutting method was used. The data collection took place on a forest enterprise, on the Vale do Rio Doce region, at the state of Minas Gerais, in Brazil, from October of 1995 to February of 1996. The studied area is inserted in the number 5 bioclimatic region of Minas Gerais, which climate is classified

1. Engenheiro Florestal, Dr., Professor Adjunto do Departamento de Ciências Florestais, Universidade Federal de Lavras, CEP: 37200-000, Lavras. (MG).

2. Engenheiro Florestal, Dr., Professor Titular do Departamento de Silvicultura e Manejo, SCA, Universidade Federal do Paraná, CEP: 80035-010, Curitiba. (PR).
\end{abstract}


as subtropical humid-subhumid, with an annual average temperature varying from 20 to $23{ }^{\circ} \mathrm{C}$; annual average precipitation varying from 1,100 to 1,400 $\mathrm{mm}$ and altitude varying from 200 to 900 $\mathrm{m}$, in salience that varies from soft wavy to mountainous. The study covered the safety aspects and injuries, with a sample of 29 chainsaw operators, working in mountain regions. Individual productivity varied from 7.98 to $13.08 \mathrm{~m}^{3} /$ day. Falling was the most dangerous daily activity. Legs and feet were the body parts more damaged with $37,4 \%$ of the injuries. In the chainsaw operators opinion, most of the accidents are caused by human actions.

Key words: Safety, ergonomics, chainsaw.

\section{INTRODUÇÃO}

O corte florestal semimecanizado com motosserra é o mais difundido no Brasil. Segundo MINETTE (1996), existiam cerca de 400.000 motosserras em atividade no Brasil no ano de 1996.

O corte com motosserra permite produtividade individual relativamente elevada, com baixo investimento inicial, podendo essa máquina ser utilizada em locais de difícil acesso às máquinas especializadas. A derrubada é considerada uma atividade perigosa, podendo o risco ser maior quando ocorrem cipós e sub-bosque. A movimentação de toras no empilhamento é uma atividade pesada e que sobrecarrega a coluna lombar, podendo ocasionar lombalgias no trabalhador. O desgalhamento, por sua vez, é uma atividade perigosa, pois a motosserra é operada em sua rotação máxima, estando sujeita a resvalos e podendo atingir o operador (SANT’ANNA, 1992).

Uma das características do corte florestal é ser um trabalho com alto risco de acidentes. Os trabalhadores atuam expostos às condições climáticas, em diferentes tipos de terreno e de florestas, sujeitos ainda a acidentes com animais peçonhentos (SODERSTROM, 1982).

A motosserra é uma máquina perigosa e seus riscos inerentes podem ser classificados, segundo SANT'ANNA (1992) em:

a) Riscos da operação, tais como rebote, queda de árvores, postura de trabalho e projeção de cavacos (serragem) nos olhos;

b) riscos do equipamento, tais como ruído, vibração, parte cortante, tanque de combustível, parte elétrica e escapamento.

É importante que as empresas florestais adquiram motosserras profissionais, equipadas com freio de corrente, pino pega-corrente, sistema anti-vibratório, protetor da mão esquerda, protetor da mão direita, trava de segurança do acelerador, direcionador de serragem e escapamento com dispositivo silencioso e direcionador de gases. Além disso, as motosserras devem ter baixo peso , design ergonômico, baixo nível de ruído e de vibração e balanceamento adequado (SANT'ANNA et al., 1995).

Segundo HASELGRUBER \& GRIFFENHAGEN (1989), para garantir a segurança no trabalho, é preciso que o operador de motosserra utilize os seguintes equipamentos de proteção individual (EPIs): capacete, protetores auriculares, protetor facial, luvas, calça de segurança e botas 
com biqueira de aço e solado antiderrapante.

Segundo HARSTELA (1987), somente os dispositivos de segurança da máquina e o uso de equipamentos de proteção individual não são suficientes para garantir a segurança do trabalhador. Também são considerados itens essenciais à segurança no corte florestal:

a) Treinamento de formação de operadores, abrangendo técnicas de operação, manutenção e segurança no trabalho;

b) observância de distância de segurança entre um operador e outro (equivalente a pelo menos duas vezes a altura da árvore), para evitar a queda de árvores sobre alguém;

c) sinalização nos limites e proximidades do talhão de corte;

d) disponibilidade de material de primeiros socorros e veículo para locomoção de feridos na área de corte;

e) uso de meios de comunicação eficientes na floresta.

Acidente, de modo geral, é toda ocorrência não-programada que altera o curso normal de uma atividade. Já o acidente de trabalho é todo aquele que decorre do exercício do trabalho, a serviço da empresa, provocando, direta ou indiretamente, lesão corporal, perturbação funcional ou doença que ocasione a morte, perda ou redução, permanente ou temporária, da capacidade de trabalho (SEGURANÇA E MEDICINA DO TRABALHO, 1992).

Os problemas econômicos acarretados pelos acidentes de trabalho atingem o acidentado, a empresa, a sociedade e o País. A redução da capacidade de trabalho, em virtude de acidente, diminui a produtividade do trabalhador, reduzindo assim as suas possibilidades de progressão na empresa, limitando o aumento salarial e a motivação de uma futura promoção. Além do custo do equipamento danificado, salários pagos para treinar o substituto, despesas médicas e farmacêuticas e queda da produção, muitos outros fatores contribuem para aumentar os custos de um acidente de trabalho (PEREIRA \& MACHADO, 1989).

Para SILVA (1989), a causa dos acidentes está vinculada à forma de realizar as tarefas. O acidente é percebido em sua relação com a forma pela qual o trabalhador realiza ou é obrigado a realizar o seu trabalho. A configuração dos acidentes está vinculada à configuração da atividade em que eles ocorrem. $\mathrm{O}$ acidente desvinculado do processo, também chamado de azar, ocorre em número mínimo e sua prevenção é praticamente impossível. Entretanto, geralmente os trabalhadores se acidentam durante as atividades para as quais estão previstos, com os equipamentos previstos e, na maioria das vezes, de forma absolutamente previsível.

Segundo MACHADO \& SOUZA (1980), anualmente ocorrem muitos acidentes na exploração florestal, grande parte deles nas operações de derrubada, desgalhamento, destopamento e toragem com motosserras, sendo a falta de experiência na atividade e a falta de treinamento pessoal as principais causas de acidentes com operadores de motosserra.

Durante muitos anos, o rebote (kick-back) foi responsável por cerca de $30 \%$ dos acidentes com operadores de motosserra. O rebote ocorre quando a ponta do sabre da motosserra toca na madeira ou outro tipo de superfície, provocando um golpe no sentido contrário, fazendo com que a 
ponta do sabre volte em direção ao corpo do operador. No fim dos anos 70 muitas motosserras foram equipadas com dispositivos anti-rebote e o número de acidentes em consequiência dos rebotes diminuiu. Em 1978, 23\% dos acidentes com motosserra, nos Estados Unidos, foram atribuídos aos rebotes (SODERSTROM, 1982).

O grande número de acidentes com motosserra na Suécia, em virtude de rebote, bem como a alta incidência da doença dos dedos brancos (má circulação sanguínea nas mãos, provocada pelas vibrações da motosserra), só começou a ser solucionado após concisas estatísticas de acidentes, e mediante pesquisa e desenvolvimento do trabalho. No fim dos anos 70, o número de acidentes com motosserra havia decrescido $85 \%$ e a ocorrência da doença dos dedos brancos, $80 \%$. Ao mesmo tempo, o número de horas de trabalho com motosserra diminuiu em torno de $20 \%$ (PETTERSSON, 1987).

HASELGRUBER \& GRIEFFENHAGEN (1989) afirmam que aproximadamente $80 \%$ dos acidentes com operadores de motosserra têm origem em falhas humanas e $20 \%$ são provenientes de causas mecânicas. As partes do corpo mais atingidas são: pernas $(30 \%)$, braços $(25 \%)$, cabeça (20\%), pés $(13 \%)$ e tronco $(12 \%)$.

FENNER (1991) estudando as partes mais atingidas pelos acidentes com motosserra, nas operações de derrubada e traçamento de eucalipto, encontrou os seguintes valores: pernas (37\%), pés $(15 \%)$, tronco $(15 \%)$, cabeça (12\%), mãos (11\%) e braços $(10 \%)$.

FORSTWIRTSCHAFTLICHE ZENTRALSTELLEDER SCHWEIZ \& STEPHANI (1987) registraram a seguinte estatística de partes do corpo atingidas em acidentes com motosserra na Suíça: $29 \%$ nas pernas (4\% nas coxas, $12 \%$ nos joelhos e $13 \%$ nas canelas); $25 \%$ nas mãos (11\% na mão e $14 \%$ nos dedos); $14 \%$ nos pés; $12 \%$ no tronco; $11 \%$ na cabeça (4\% nos olhos e $7 \%$ na cabeça) e $9 \%$ nos braços (4\% nos antebraços e $5 \%$ nos braços).

Os quase-acidentes adquiriram importância a partir de um estudo que ficou conhecido como pirâmide de Bird. O autor demostrou que, para cada lesão incapacitante, ocorrem 100 lesões leves e 500 quase-acidentes. A existência de correlação entre a freqüência de acidentes e a frequência de quase-acidentes já foi demonstrada em outras experiências (Sartor ${ }^{1}$ apud FENNER, 1991).

Entretanto, embora os quase-acidentes possam ser observados e registrados, não foram encontradas estatísticas a esse respeito na atividade de corte florestal com motosserra.

Os objetivos do presente trabalho foram a investigação das principais causas de acidentes no trabalho com motosserra, as partes do corpo mais atingidas e as atividades parciais mais perigosas.

\section{MATERIAIS E MÉTODOS}

A coleta de dados foi iniciada em outubro de 1995 e concluída em fevereiro de 1996, tendo sido realizada em plantios de Eucalyptus spp, nas áreas montanhosas de uma empresa florestal, no Vale do Rio Doce, em Minas Gerais.

\footnotetext{
${ }^{1}$ SARTOR, J.E. Cercando o quase acidente. Proteção, Campo Bom, v.2, n.7, p.51-53. 1990.
} 
Foram coletadas informações de 29 operadores de motosserra, número que correspondia a $45,13 \%$ dos operadores de motosserra da empresa que atuavam em áreas montanhosas.

\section{Área de estudo}

A coleta de dados foi feita em uma empresa florestal de Minas Gerais, nos Municípios de Marliéria e Córrego Novo, em plantios comerciais de Eucalyptus spp, em regime de corte raso, localizados em terrenos com relevo variando de forte ondulado (declividades entre 20 e $45 \%$ ) a montanhoso (declividades entre 45 e $75 \%$ ). A espécie predominante foi Eucalyptus torelliana.

A área de estudo está compreendida na região bioclimática número 5 do Estado de Minas Gerais cujo clima é classificado como subtropical úmido-subúmido, com temperatura média anual variando de 20 a $23^{\circ} \mathrm{C}$, precipitação média anual variando de 1.100 a $1.400 \mathrm{~mm}$ e altitude de 200 a $900 \mathrm{~m}$, em relevo que varia de suave ondulado a montanhoso (GOLFARI, 1975).

As médias de temperatura máxima em dezembro de 1995, janeiro e fevereiro de 1996 foram, respectivamente: $29,4{ }^{\circ} \mathrm{C}, 31,7{ }^{\circ} \mathrm{C}$ e $34,0{ }^{\circ} \mathrm{C}$. As médias de umidade relativa do ar nos meses de dezembro de 1995, janeiro e fevereiro de 1996 foram, respectivamente: 82,0\%, 74,5\% e 73,9\%. A precipitação mensal nos meses de dezembro de 1995 e janeiro de 1996 foram, respectivamente: 665 $\mathrm{mm}$ e $94 \mathrm{~mm}$, enquanto que em fevereiro de 1996, a coleta abrangeu apenas os 15 primeiros dias do mês $(15 \mathrm{~mm})$.

\section{Método de corte florestal}

A empresa utiliza o corte raso, semimecanizado, sendo empregadas motosserras profissionais de 3,0 KW de potência, equipadas com sabre de $37 \mathrm{~cm}$ de comprimento, efetuando a derrubada e o traçamento, e ainda, machados que efetuam o desgalhamento, no sistema $1+1$ (um operador e um ajudante). Cada dupla trabalha com eitos de quatro ou cinco linhas de plantio, a critério do coordenador de área ou supervisor. O corte começa pela parte mais baixa do terreno e termina na parte mais alta. $\mathrm{O}$ empilhamento da lenha é feito por outra equipe, até 30 dias após o corte.

A bitola comercial é de $2,20 \mathrm{~m}$, em virtude das dimensões dos fornos das carvoarias. $\mathrm{O}$ espaçamento de plantio predominante é de $3 \times 2 \mathrm{~m}$.

O horário de trabalho é de 6 às 15 horas, de $2^{\mathrm{a}}$ a $6^{\mathrm{a}}$ feira e em sábados alternados, com intervalo de uma hora para almoço, das 11 às 12 horas. Ou seja, a jornada de trabalho semanal é de 44 horas, incluindo o tempo de transporte.

O local onde os trabalhadores fazem suas refeições é preparado, abrindo-se uma pequena clareira na qual é montada uma estrutura de madeira coberta com lona, com dimensões de $3 \mathrm{~m}$ (largura) x 8,00 m (comprimento) x 1,50 m (altura). Troncos roliços apoiados em toretes funcionam como banco. Improvisa-se também uma estante de madeira para uso do coordenador de área.

O transporte dos operadores de motosserra da sede da Empresa até o campo é feito em ônibus particular, com 45 lugares. O ônibus transporta, ainda, a carretinha que leva as motosserras, machados e combustíveis. 


\section{RESULTADOS E DISCUSSÃO}

\section{Produtividade no trabalho}

A produtividade individual, obtida a partir de dados históricos, variou de 7,98 $\mathrm{m}^{3} / \mathrm{dia}$ a 13,08 $\mathrm{m}^{3} /$ dia, sendo a média de $10,28 \mathrm{~m}^{3} /$ dia, para uma jornada de trabalho de oito horas por dia. Essa média foi ligeiramente superior à média dos operadores que tiveram seus tempos e movimentos cronometrados que foi de $10,04 \mathrm{~m}^{3} /$ dia.

\section{Segurança no trabalho}

Todos os operadores entrevistados consideraram necessária a utilização de todos os equipamentos de proteção individual (calça de segurança, botinas de segurança, luvas de segurança, protetor facial ou óculos especial, protetores auriculares e capacete de segurança).

O protetor facial é o equipamento de segurança que causa maior incômodo, na opinião de $40,6 \%$ dos entrevistados, seguido do protetor auricular, apontado por 12,5\% dos entrevistados (Tabela 1).

TABELA 1: Incômodos causados pelos equipamentos de proteção individual de uso obrigatório para operadores de motosserra.

\begin{tabular}{lc}
\hline \multicolumn{1}{c}{ EQUIPAMENTO DE PROTEÇÃO INDIVIDUAL } & QUEIXA DE INCÔMODOS (\%) \\
\hline Protetor facial & 40,6 \\
Protetor auricular & 12,5 \\
Nenhum & 46,9 \\
\hline TOTAL & 100 \\
\hline
\end{tabular}

A maioria dos operadores de motosserra $(58,6 \%)$ afirma que já deixou de sofrer um acidente de trabalho por estar utilizando corretamente o equipamento de proteção individual.

\section{Acidentes no trabalho}

Os operadores de motosserra entrevistados, que já sofreram acidente de trabalho na empresa, representaram 44,8\% da amostra. A maior parte destes sofreu um acidente, entretanto 13,7\% sofreram dois acidentes e 3,4\% sofreram três acidentes.

A Figura 1 mostra a frequiência de acidentes com operadores de motosserra, em relação às partes do corpo atingidas. Predominam os acidentes ocorridos nos membros inferiores (nas pernas e nos pés), com $37,4 \%$ somados. 


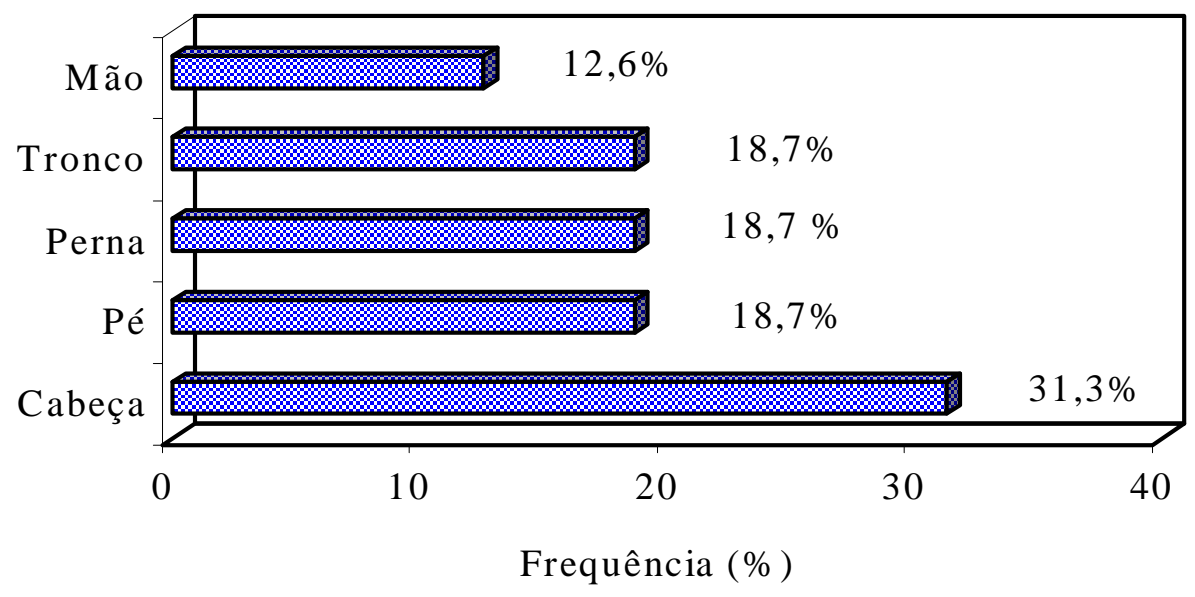

FIGURA 1: Partes do corpo atingidas em acidentes com operadores de motosserra.

$\mathrm{Na}$ Tabela 2, são apresentados os resultados obtidos neste estudo com dados de literatura. No estudo atual, a parte do corpo mais atingida foi a cabeça, enquanto nos demais trabalhos as partes mais atingidas foram pernas e braços. Entretanto, em todos os trabalhos predominaram os acidentes na metade inferior do corpo (pernas e pés).

TABELA 2: Comparação do estudo atual com outros trabalhos de investigação de acidentes com operadores de motosserra, em relação às partes do corpo atingidas (em porcentagem).

\begin{tabular}{l|c|c|c|c}
\hline & SANT'ANNA $^{1}$ & FENNER $^{2}$ & HASELGRUBER $^{3}$ & STEPHANI $^{4}$ \\
\hline Cabeça & 31,3 & 12 & 20 & 11 \\
Tronco & 18,7 & 16 & 12 & 12 \\
Braços $*$ & 12,6 & 21 & 25 & 34 \\
Pernas & 18,7 & 37 & 30 & 29 \\
Pés & 18,7 & 15 & 13 & 14 \\
\hline TOTAL & 100 & 100 & 100 & 100 \\
\hline
\end{tabular}

Sendo: ${ }^{*}=$ Inclui acidentes nos braços e nas mãos $;{ }^{1}=$ Dados do presente trabalho; ${ }^{2}=$ Fonte: FENNER (1991), relativo a acidentes ocorridos nas atividades de derrubada e traçamento de eucalipto, em Minas Gerais, Brasil; ${ }^{3}=$ Fonte: HASELGRUBER \& GRIEFFENHAGEN (1989); ${ }^{4}=$ Fonte: FORSTWIRTSCHAFTLICHE ZENTRALSTELLEDER SCHWEIZ \& STEPHANI (1987), relativo a acidentes com operadores de motosserra da Suíca.

A Tabela 3 mostra o tipo de atividade que causou o acidente. A derrubada com motosserra foi a atividade na qual ocorreu o maior número de acidentes $(40,0 \%)$.

Com relação aos quase-acidentes, 55,2\% dos operadores de motosserra declararam já ter passado por essa experiência. A maioria deles lembrou-se de ter experimentado apenas um quaseacidente, mas 6,9\% lembraram-se de ter experimentado dois quase-acidentes. 
TABELA 3: Freqüência de acidentes entre operadores de motosserra por atividade.

\begin{tabular}{lc}
\hline \multicolumn{1}{c|}{ Ativividade } & Frequência (\%) \\
\hline Derrubada com motosserra & 40,0 \\
Carregamento manual & 13,3 \\
Carvoejamento & 13,3 \\
Derrubada com machado & 6,7 \\
& \\
Traçamento com motosserra & 6,7 \\
Traçamento com machado & 6,7 \\
Desgalhamento com machado & 6,7 \\
Empilhamento manual & 6,7 \\
\hline TOTAL & 100 \\
\hline
\end{tabular}

A Tabela 4 mostra que a maior freqüência de quase-acidentes ocorreu na derrubada, com $58,8 \%$ dos casos.

TABELA 4: Atividades nas quais ocorreram quase-acidentes entre operadores de motosserra.

\begin{tabular}{lc}
\multicolumn{1}{c|}{ Atividade } & Frequência (\%) \\
\hline Derrubada com motosserra & 58,8 \\
Traçamento com motosserra & 29,4 \\
Caminhamento & 11,8 \\
\hline TOTAL & 100 \\
\hline
\end{tabular}

Dentre os operadores de motosserra entrevistados, $89,6 \%$ consideram o seu trabalho perigoso e $72,4 \%$ consideram a derrubada a atividade mais perigosa.

Indagados sobre o que eles consideram ser a maior causa de acidentes de trabalho na atividade do operador de motosserra, 35,0\% apontaram a "falta de atenção por parte do operador" como a principal responsável (Tabela 5).

TABELA 5. Principais causas de acidentes de trabalho, na opinião dos operadores de motosserra.

\begin{tabular}{lc}
\hline \multicolumn{1}{c}{ Causas de acidentes no corte florestal } & Frequência (\%) \\
\hline Falta de atenção por parte do operador & 35,0 \\
Erros do operador & 15,0 \\
Preocupações diversas & 12,5 \\
Pressão para que o trabalho seja produtivo & 7,5 \\
Periculosidade inerente à atividade & 5,0 \\
Área mal roçada (presença de sub-bosque) & 5,0 \\
Condições florestais (cipós, queda de galhos, tocos, etc.) & 5,0 \\
Falta de conhecimento sobre a operação ou equipamento & 5,0 \\
Negligência & 5,0 \\
Fatalidade & 2,5 \\
Não soube dizer & 2,5 \\
\hline TOTAL & 100,0 \\
\hline
\end{tabular}


Nota-se que as três principais causas, por frequiência de citações $(62,5 \%)$, atribuem a responsabilidade do acidente ao próprio operador. No total, $72,5 \%$ das citações referem-se a falhas humanas como causas de acidentes, na opinião dos próprios operadores de motosserra. Esse resultado é semelhante à afirmação de HASELGRUBER \& GRIEFFENHAGEN (1989) de que 80\% dos acidentes com operadores de motosserra têm origem em falhas humanas.

\section{CONCLUSÕES}

Tendo por objetivo a análise da segurança no trabalho no corte de eucalipto com motosserra em região montanhosa, foram avaliados 29 operadores de motosserra, chegando-se às seguintes conclusões:

- A derrubada foi atividade na qual ocorreu o maior número de acidentes entre os operadores de motosserra. $\mathrm{Na}$ maior parte dos acidentes as partes do corpo mais atingidas foram os membros inferiores (pernas e pés).

- A falta de atenção por parte do operador foi apontada como a principal causa de acidentes no corte florestal, pelos próprios operadores de motosserra. As causas humanas, somadas, representaram a opinião de $72,5 \%$ dos operadores de motosserra.

\section{REFERÊNCIAS BIBLIOGRÁFICAS}

FENNER, P. T. Estudo descritivo de acidentes do trabalho em uma empresa florestal. Curitiba, 1991. 140 f. Dissertação (Mestrado em Engenharia Florestal) - Setor de Ciências Agrárias, Universidade Federal do Paraná.

FORSTWIRTSCHAFTLICHE ZENTRALSTELLE SCHWEIZ \& STEPHANI, P. Die Holzernte. Basel: Friedrich Reinhardt Verlag. 1987. 424 p.

GARROW, J.S. Treat obesity seriously: a clinical manual. Edinburg: Churchill Livingstone, 1981. $365 \mathrm{p}$.

GOLFARI, L. Zoneamento ecológico do Estado de Minas Gerais para reflorestamento. Belo Horizonte: PNUD/FAO/IBDF, 1975. 65 p. (Série técnica).

HARSTELA, P. Ergonomics applied to forestry. In: SEMINAR ON ERGONOMICS APPLIED TO LOGGING (1983: Dehra Dun, India). Proceedings... Helsinki, FTP / FINNIDA,1987a. p. 113-131.

HARSTELA, P. Introduction to ergonomics. In: SEMINAR ON ERGONOMICS APPLIED TO LOGGING (1983: Dehra Dun, India). Proceedings... Helsinki, FTP / FINNIDA, 1987b. p. 3962.

HASELGRUBER, F.; GRIEFFENHAGEN, K. Motosserras: mecânica e uso. Porto Alegre: 
Metrópole, 1989. $136 \mathrm{p}$.

MACHADO, C.C.; SOUZA, A.P. Segurança no trabalho com motosserras. Viçosa: UFV, 1980. 10 p. (Boletim de Extensão, 21).

MINETTE, L.J. Análise de fatores operacionais e ergonômicos na operação de corte florestal com motosserra. Viçosa, 1996. 211 f. Tese (Doutorado em Ciência Florestal) - Departamento de Engenharia Florestal, Universidade Federal de Viçosa.

PEREIRA, A.R.; MACHADO, C.C. Segurança do trabalho na empresa. Viçosa: UFV, 1989. 11 p.

PETTERSSON, B. Forest-worker training and other ways to increase efficiency and enhance safety and health at work. In: Simpósio sobre Exploração, Transporte, Ergonomia e Segurança em Reflorestamentos (5.: 1987: Curitiba). Anais... Curitiba: Fupef, 1987. p. 322-333.

SANT'ANNA, C.M. Fatores humanos relacionados com a produtividade do operador de motosserra no corte florestal. Viçosa, 1992. 142 f. Dissertação (Mestrado em Ciência Florestal) - Departamento de Engenharia Florestal, Universidade Federal de Viçosa.

SANT'ANNA, C.M.; GIULIANO, C.V.; YAMASHITA, R.Y.; CHAVES, A.A.; CARDOSO, A.L.M. Melhoria das condições de trabalho com motosserra. In: SIMPÓSIO BRASILEIRO SOBRE COLHEITA DE MADEIRA E TRANSPORTE FLORESTAL (2.: 1995: Salvador). Anais... Viçosa: SIF, 1995. p. 173-186.

SEGURANÇA E MEDICINA DO TRABALHO. 21. ed. São Paulo: Atlas, 1992. 404 p. (Manuais de Legislação Atlas, 16).

SILVA, M.C.R. Ergonomia e estudo de acidentes no trabalho. In: SEMINÁRIO BRASILEIRO DE ERGONOMIA (4.: 1989: Rio de Janeiro). Anais... Rio de Janeiro, 1989. p. 477-478.

SODERSTROM, N. Chainsaw savvy: a complete guide. New York: Morgan \& Morgan, 1982.144p. 